EROJA ARJESSA

\title{
Kohtaamisen mahdollisuudet ja rajat monikulttuurisessa tanssiprojektissa
}

\begin{abstract}
Olin seuraamassa Kuun taikoja -nimistä tanssiesitystä Itä-Helsingin kulttuurikeskus Stoassa lokakuussa 2004. Lähes kaikki esiintyjät olivat itämaisen $\operatorname{tanssin}^{1}$ harrastajia tai opettajia, mutta esityksessä nähtiin paljon muutakin: muun muassa Irakin kurdien tanssia sekä ns. fuusiotanssia, jossa sekoitellaan vaikutteita eri tanssilajeista. Esityksen taustalla oli puolitoista vuotta kestänyt projekti, jonka tarkoituksena oli työstää ryhmässä erilaisten toiminnallisten menetelmien avulla naisten elämään liittyviä yhteisiä teemoja ja tuottaa niistä tansseja. Monikulttuurisuus oli lähtökohtana muun muassa siten, että osallistujiksi haluttiin monenlaisia naisia ja tyttöjä eri kulttuureista, tanssitaustoista ja ikäryhmistä.
\end{abstract}

Esitystä luonnehdittiin ennakkoon itämaisen tanssin tapahtumissa jaossa olleissa lehtisissä seuraavasti:

\footnotetext{
Tanssin ja leikin keinoin haluamme edistää maahanmuuttajien ja suomalaisten kohtaamista sekä osaltamme vähentää ennakkoluuloja ja syrjintää. Näytöksen teemana on naiseus eri kulttuureissa - naisen elämän solmukohdat, kohokohdat ja ilon aiheet. Ilmaisumuotonamme on pääosin itämainen tanssi, mausteena käytämme myös fuusiotanssia sekä virtuaalitekniikkaa. (Kuun taikoja -ennakkomainos.)
}

Juuri esitykset nähtyäni olin vaikuttunut ja liikuttunut siitä energiasta ja innosta, jolla naiset olivat esityksessä mukana. Mielestäni esityksen tekotavassa oli jotakin itämaisen tanssin kentällä uutta ja ennennäkemätöntä (ks. Laukkanen 2003b). Projektin palautetilaisuus ja ensimmäiset haastattelut vahvistivat näkemystäni hedelmällisestä yhteistyöstä erilaisista taustoista tulevien naisten kesken. Näkemykseni kuitenkin muuttui keskusteltuani kahden maahanmuuttajataustaisten osallistujan ja heidän suomalaisen kontaktihenkilönsä kanssa. Kriittiset puheenvuorot marginalisoiduiksi tulemisen kokemuksista vaivasivat, ja koin tarvetta ja halua antaa äänen näille kertomuksille. Myöhemmissä haastatteluissa kävi ilmi myös, että maahanmuuttajataustaisten naisten rekrytointi projektiin oli ollut haastavaa ja epäonnistakin. Suomalaisten taholta projektiin sisältyikin yhtäältä halu tehdä hyvin ja luoda mahdollisuus erilaisten naisten yhteiseen tekemiseen. Toisaalta moninaisuuksien ja erojen edessä koettiin pelkoa ja syyllisyyttä siitä, että tekeekin väärin. 
Tutkin artikkelissani, miten Kuun taikoja -projektin eri tasoilla uusinnettiin, purettiin ja liikutettiin käsityksiä eroista ja monikulttuurisuudesta. Viittaan näillä eri tasoilla ensinnäkin projektin arkeen ja organisaatioon, toiseksi näyttämölle vietyyn monikulttuurisuuden tanssilliseen representaatioon ja kolmanneksi tutkimusta varten tuotettuun haastattelupuheeseen. Yksi projektin lähtökohdista oli edistää maahanmuuttajien ja suomalaisten kohtaamista. Tarkastelenkin, millaiset kohtaamiset monikulttuurisuutta korostavassa projektissa olivat ylipäänsä mahdollisia ja millaisin ehdoin.

Tartun artikkelissani tanssiesitysten ja tanssijoiden puheen sellaisiin kohtiin, jotka häiritsivät ja liikuttivat kaksinapaisuuteen perustuvia rajoja. Näissä kohdissa on voimakas ambivalenssin tunne. Kulttuurintutkija Ien Ang (2001) on liittänyt erojen kahtaalle vetävän voiman, ambivalenssin, olennaiseksi osaksi monikulttuurista ideologiaa. ${ }^{2}$ Rakenteellisella tasolla ambivalenssi ilmenee toisaalta juhlittavien, toisaalta häiriöitä tuottavien erojen välisen jännitteen jatkuvana neuvotteluna. Moninaisuutta juhlistava retoriikka ja käytännöt pyrkivät vaimentamaan vaikeasti ylitettäviin eroihin ja konflikteihin liittyvät seikat, jotta monikulttuurinen maailmankuva säilyisi. Tästä torjunnasta seuraa, että ambivalenssi on aina läsnä monikulttuurisissa kohtaamisissa. Rakenteellisen tason ambivalenssin torjunta näkyy myös subjektiivisella tasolla enemmistö- ja vähemmistösubjektien välisissä suhteissa kummallisina tilanteina, tietynlaisina katseina ja "viattomina" vähemmistösubjektin alkuperää koskevina kysymyksinä. Monikulttuurisen ideologian vaatimus suvaitsevaisuudesta tuottaa aina hierarkian suvaitsevan ja suvaittavaksi rakentuvan subjektin välille, ja siten myös eron itsen ja toisen välille. (Ang 2001: 142-145.)

Ang korostaa nimenomaan arjen mikropolitiikkaa ja hybridisyyden epädramaattisuutta. Nämä ovat läsnä kaikkialla, missä ihmiset elävät samassa maailmassa ja joutuvat neuvottelemaan paikastaan ja toisten ymmärtämisen mahdollisuuksista (Ang 2001: 71-73; 198; Ang 1997: 59). Hybridisyyteen usein liitetyn kumouksellisuuden korostamisen sijaan olisi olennaista tarkastella hybridisyyteen liittyviä yhteismitattomuuden, ymmärtämättömyyden ja ulossulkemisen prosesseja. Kohtaamiseen liittyvän konfliktin edessä voi toimia kuitenkin monin tavoin. Toisen ero voidaan pyrkiä sulauttamaan samuuteen, tai se voidaan torjua täysin vieraana ja käsittämättömänä. Eron voi antaa myös liikuttaa ja muuttaa itseä. (Anthias 2001: 628; Ahmed 2000: 151.)

Artikkelini jakautuu neljään osaan. Ensimmäiseksi tartun sekä tanssillisesti esitettyyn että haastattelupuheessa tuotettuihin arjen esityksiin. Suorittaja-tanssi kuvasi useista tanssityyleistä lainailevan fuusioliikekielen avulla arkea ja sen toistuvuutta, ja luenkin sitä suhteessa haastateltavien puheeseen eroista ja yhtäläisyyksistä suomalaisten ja maahanmuuttajanaisten arjessa. Toiseksi nostan esille kysymyksen kulttuurisesti vastuullisista ja eettisistä representaatioista, joita käsittelen erityisesti esityksessä nähtyjen jinnien, taikaolentojen kautta. Kolmanneksi käsittelen osallistujien odotuksia monikulttuurisen ryhmätyön suhteen sekä odotusten täyttymisen ehtoja. Viimeiseksi analysoin ystävyyttä käsittelevän kurditanssin valmistamisen prosessia, johon liittyi 
sekä konflikteja että liikuttavia kohtaamisia.

Aineistoani ovat tanssijoiden kanssa käydyt keskustelut, nauhoitetut haastattelut, omat havainnot ja muistiinpanot esitystilanteissa, karonkassa ja palautetilaisuudessa sekä videotallenne esityksistä. Käytössäni on myös äänitallenne palautetilaisuudesta. Tutkittavat ovat esityksessä tanssineita suomalaisia ja muualta Suomeen muuttaneita itämaisen tanssin harrastajia, opettajia ja esittäjiä (22 tanssijaa, joista viisi kouluikäistä tyttöä ja kaksi maahanmuuttajataustaista naista), joista osaa olen haastatellut kevään ja kesän 2004 aikana sekä ryhmässä että yksittäin. ${ }^{3}$ Haastatteluihin on osallistunut yhteensä kymmenen esiintyjää. ${ }^{4}$

Projektissa oli vain kaksi muualta Suomeen muuttanutta naista, ja sainkin yhdeltä suomalaiselta osallistujalta palautetta siitä, että he edustavat tekstissäni kokonaista ryhmää (KT3). Kysymys edustavuudesta nousi esille myös Kuun taikoja -projektissa. Kategorisoinnin voima häivyttääkin helposti maahanmuuttajien väliset erot (Huttunen 2004: 138). En kuitenkaan pyri esittämään osallistujia sen kummemmin ryhmän jäseninä kuin yksilöinäkään, joilla olisi ennalta määrätty identiteetti, vaan tarkastelen ennemminkin millaisia paikkoja monikulttuurisuuden ja erojen diskurssit heille tarjosivat.

Eri roolien yhdistäminen ja tasapainottelu tutkittavien odotusten välillä on ollut haastavaa. Alun perin minua pyydettiin kirjoittamaan esityksestä arvio itämaisen tanssin harrastajille suunnattuun Afsana-lehteen (Laukkanen 2003b), ja hieman ennen näytöksiä kerroin tutkimusintresseistäni ja tarjouduin avustajaksi. Esityksiä oli kaksi saman päivän aikana, joista ensimmäisen seurasin katsomosta käsin. Ennen esityksiä sekä toisen näytöksen aikana avustin esiintyjiä nopeissa pukujen vaihdoissa sekä ruoka- ja juomahuollossa. Takahuoneessa keskustelin esiintyjien kanssa näytöksestä ja omasta tutkimuksestani. Esitysten jälkeen kokoonnuimme kaikki ravintolaan juhlimaan. Noin kuukauden kuluttua esityksistä pidettiin palautetilaisuus, jossa hyödynnettiin toiminnallisia ryhmämenetelmiä prosessin purkamiseksi. Seurasin tilaisuutta sivusta muistiinpanoja tehden ja nauhuri pyörien.

Olin siis mukana toisaalta mahdollistamassa näytöksen toteutumista ruokkivine, pukuja napittavine ja kenkiä ojentelevine käsineni, toisaalta toin esitykselle julkisuutta kirjoittamalla siitä arvion. Haastatteluissa esiintyjille on tarjoutunut tilaisuus muistella näytöstä ja sen aiheuttamia tunnelmia. Erityisesti marginalisoiduksi itsensä kokeneet osallistujat purkivat haastatteluissa kipeitä tuntoja, joita ei varsinaisen projektin aikana ollut tilaisuutta käsitellä. Osittain minuun on kohdistettu varmasti myös toiveita, että toimisin viestinviejänä niiden tanssijoiden välillä, jotka eivät enää ole tekemisissä toistensa kanssa. Tutkittavat ovat saaneet itselleen omista haastatteluistaan puhtaaksikirjoitetut versiot, ja ainakin osa on lukenut niitä mielenkiinnolla. He ovat lukeneet ja kommentoineet myös artikkelin käsikirjoitusversiota. 


\section{Monikulttuurista arkea?}

Useimmiten itämaisen tanssin esitykset Suomessa tuotetaan niiden tanssien pohjalta, joita esiintyjillä on jo valmiina vaikka näytöksessä tai esityksessä olisikin jokin yhteen kokoava teema tai juonirakenne. Kuun taikoja -tanssiesityksen alkuidea tuli yhdeltä suomalaiselta itämaisen tanssin opettajalta, mutta ajatuksena oli tuottaa ja toteuttaa esityksessä käsiteltävät teemat eri kulttuureista tulevien naisten ja tyttöjen ryhmätyönä. ${ }^{5}$ (TKU/A/06/52:3.) Tähän liittyi myös odotuksia ja toiveita osallistujien ilmaisu- ja tanssitaidoista: "jos se ois ihmisillä se kroppa enemmän jo instrumenttina, niin sitä voi käyttää semmosena pensselinä, sen oman sisäisen ideamaailman toteuttamiseen" (TKU/A/06/52:10). Puolitoista vuotta kestäneessä prosessissa oli apuna teatteri-ilmaisunohjaaja, joka pyrki avustamaan varsinaisia tekijöitä erilaisilla toiminnallisilla ryhmätyömenetelmillä (TKU/A/06/52:4). Prosessin edetessä esityksen teemoiksi kiteytyivät arki ja sen toistuvuus, ulkopuolisuus, hoivaaminen, ystävyys, huumori, taikuus, naisen heikkous ja vahvuus. (Kuun taikoja -käsiohjelma.) Pyrkimys oman arjen esittämiseen erotti projektin monista muista itämaisen tanssin näytöksistä, joissa ollaan melko uskollisia tanssin "kotimaissa" esitettävälle itämaisen tanssin eikertovalle muodolle (esim. Adra 2005: 41) ja pyritään sekä liikkeiden, tulkinnan että ulkoisen olemuksen avulla arjen ja arkisten asioiden yläpuolelle. Myös halu purkaa stereotyyppisiä käsityksiä naisista, lapsista ja eri kulttuureista oli tärkeä lähtökohta.

Osallistujat olivat kolmen itämaisen tanssin opettajan oppilaita - kaikki naispuolisia, kuten itämaisen tanssin harrastajatkin enimmäkseen. Projektiin etsittiin maahanmuuttajataustaisia yhteistyökumppaneita usealta taholta ( $\mathrm{mm}$. Kassandra ry, Urban-hanke) mutta yksi toisensa jälkeen lupaaviltakin näyttäneet kontaktit jäivät tuloksettomiksi. ${ }^{6}$ Projektin vetäjät nimesivät tähän suurimmaksi syyksi maahanmuuttajanaisten käytännön ongelmat arjen järjestämiseksi Suomessa sekä oman kyvyttömyytensä vastata näihin tarpeisiin esimerkiksi lastenhoitojärjestelyillä. Haastattelupuheessa korostui maahanmuuttajanaisten rekrytoimiseksi käytetty energia ja aika ja myös projektiin mukaan saatujen kaksikulttuuristen lasten eteen nähty vaiva kyytien järjestämisineen. Toinen projektin vetäjistä kommentoi vaikeuksia seuraavasti:

\footnotetext{
Mut jotta me oltais saatu niille kotiäideille, niille somalinaisille markkinoitua ja heidät mukaan niin meiän ois, siin ois pitäny olla, massiivinen lastenhoito järjestää ja kaikki tämä, että heiän oma elämänsä ei saanu, se arkielämä ei saanu tavallaan niinku häiriintyä siitä että he tuo sitä, tanssii ja tuo sitä omaa kulttuuriaan. (TKU/A/06/52:5.)
}

Toinen projektissa mukana olleista maahanmuuttajanaisista kertoi haastattelussa nimenomaan arjen järjestämisen olleen hankalaa: harjoituspaikkoihin oli vaikeaa tulla, päivät venyivät pitkiksi ja lapsi joutui olemaan yksin kotona (KT1:2, ks. myös TKU/ A/06/50a: 24). ${ }^{7}$ Eräs suomalainen haastateltava pohti eroja arjessa seuraavasti: 
Että mulle tuli semmonen tunne että tässä kohtaa todella kaks aivan eri arkee. Et vaikka se oli treenisalilla semmonen hetki mut että tajus että (--). Että vaikka siellä on jotain samaa, lapsiin, perheeseen, hoivaamiseen, tämmösiin liittyviä yhteisiä teemoja, niin sitten kuitenkin se perusarki ja ne olosuhteet, missä eletään, on jotenkin aika eri tasoilla mennään. Meillä on jotenkin sitä aikaa ja mahdollisuutta kuitenkin panostaa vapaaaikaan ja itseilmaisuun ja tanssiin ja siihen harrastamiseen ja nää naiset on sen todella aika tiukan arkensa kanssa, elävät Suomessa elämää ja ei oo lapsenhoitoo, ei oo yhtään mitään. (TKU/A/06/52:6.)

Haastateltavan sitaatissa huomiota kiinnittävät "semmonen tunne" ja "semmonen hetki" treenisalilla, jossa pyrittiin jakamaan ja luomaan yhteistä tilaa kokemusten jakamiselle. Luen tätä ambivalenssin hetkenä, hetkellisenä ylittämättömien erojen läsnäolona. Toisaalta kiireisen arjen nähtiin olevan puolin ja toisin kaikille yhteistä (KT1:2, TKU/A/06/52:10), mutta silti erot "meidän" ja "näiden" välillä tuntuivat ylittämättömiltä. Haastateltavalla oli kyllä tahtoa ja pyrkimystä korostaa samuutta ja häivyttää konflikteja, mutta "semmonen tunne" pakotti näkemään myös ongelmia erilaisten naisten yhteistyön sovittamisessa. Ongelmat jäivät projektin aikana osittain tietoisen käsittelyn ulkopuolelle johtuen ensinnäkin siitä, että näytös piti saada valmiiksi, mutta toiseksi myös siksi, että näitä ristiriitoja ei ehkä osattu odottaa (TKU/A/06/51:1). Erityisesti maahanmuuttajien osallistumiseen liittyviä ristiriitoja ei otettu eksplisiittisesti puheeksi myöskään projektin palautetilaisuudessa. Kumpikaan maahanmuuttajanaisista eikä myöskään heidän opettajansa tullut tilaisuuteen paikalle. Syiksi mainittiin poisjääneen tanssinopettajan jo ennalta tiedossa ollut työtilaisuus sekä palautesession osuminen ramadanin vieton kannalta hankalaan aikaan (ks. myös KT1:5). Tämä osoittaa juuri arjen keskeisyyden monikulttuuristen kohtaamisten paikkana ja tilana, johon voidaan aika helpostikin evätä tai mahdollistaa kaikkien pääsy. Palautetilaisuutta leimasi suomalaisnaisten ja osin lastenkin yhteinen ilo ja jakaminen onnistuneesta ja tunteita herättäneestä projektista.

Vaikka haastateltavat eivät eksplisiittisesti kytkeneet naisten erilaisten arkien törmäystä esityksessä nähtyyn toisteista arkea käsittelevään Suorittaja-tanssiin, liitän luennassani yhteen esityksen tuottamiseen hyvinkin konkreettisesti ja materiaalisesti vaikuttaneet naisten arjet sekä tanssillisesti esitetyn arjen.

\section{Suorittaja-tanssi}

Suorittaja-tanssissa kolme suomalaista tanssijaa liikkuu robottimaisesti tympääntyneen näköisenä arjen rutiineja toistaen monotonisen, luuppeja sisältävän elektronisia ääniä ja intialaista rumpua muistuttavaa ääntä yhdistelevän musiikin tahtiin. Yksi korjailee pakonomaisesti huulipunaansa kimaltelevassa mekossaan kuvitteellinen peili kädessään, toinen tiskaa astioita esiliina edessään välillä hikeä otsaltaan pyyhkien ja 
kolmas kirjoittaa kiivaasti koneella kravatti kaulassaan. Huulipunaansa korjaileva tanssija jää yhtäkkiä tuijottamaan suoraan eteensä aivan kuin vasta nyt huomaisi olevansa yleisön edessä. Tanssija työntää päätään eteenpäin ja siristää silmiään nähdäkseen paremmin. Yhtäkkiä tanssijan oikea olkapää alkaa tehdä ympyrää, jota hän katsoo ihmetellen. Koko käsivarsi tulee mukaan liikkeeseen, johon kaksi muuta tanssijaa yhtyvät. Liike muuttuu paikallaan tehdyksi vatsan undulaatioksi, ${ }^{8}$ ja tanssijoiden ilmeet alkavat muistuttaa iloa ja nautintoa. Undulaatio on iso ja pehmeä liike, tässä yhteydessä kuitenkin selkeästi liioiteltu versio perinteisessä itämaisessa tanssissa nähdystä liikkeestä.

Seuraavaksi tanssijat kävelevät pienin, jäykin askelin jonoon ja jatkavat yhden tanssijan aiemmin esittämää kirjoituskoneella kirjoittamista. Tätä ei kestä kuitenkaan kauan, kun tanssijat taas erkanevat ja alkavat tanssia hip hop -tyyliin hyppien, isoja liikkeitä tehden. Tässä kohtaa nähdään myös itämaisesta tanssista tuttuja tyyliteltyjä lantionkahdeksikkoliikkeitä. Tanssijat katsovat omaa ruumistaan kuin ihmetellen sen kykyä liikkua. Tämän osan lopussa tanssijat tekevät käsillään hip hop -videoista tuttuja liikkeitä. Sitten he palaavat alun arkisiin tehtäviin. Lopussa musiikin tahti kiihtyy, tanssijat vaihtavat paikkoja ja alkavat pyöriä ympäri kunnes lopulta kaatuvat lattialle. Vain laulajan huokaileva ääni sekä sydämen pamppailua muistuttava ääni jäävät soimaan. Hetken maattuaan he nousevat ylös, ja heidän tilalleen tulee makaamaan kolme suomalaisia muinaispukuja muistuttaviin asuihin pukeutunutta huivipäistä tanssijaa. He esittävät väsyneitä, vaivaisia naisia, joiden tanssi jatkuu Värttinän Viikon vaivane -kappaleen soidessa.

Millaisia merkityksiä tanssi saa kun sitä tarkastellaan osana monikulttuurisuuden diskurssia ja projektin arkea? Suorittaja-tanssin liikekieltä kuvailtiin haastattelussa fuusioliikekieleksi. Tavallisesti itämaisen tanssin harjoittajat ymmärtävät fuusion eri kulttuureista ja tyyleistä poimittujen musiikillisten, puvustuksellisten ja liikkeellisten elementtien yhdistelmänä (TKU/A/06/52:2). ${ }^{9}$ Tällaista fuusiotanssikäsitystä voi pitää "irtokarkkietnisyyden" ${ }^{10}$ representaationa, jossa valitaan, shoppaillaan ja kulutetaan erilaisia etnisiä symboleja ja sulautetaan ne osaksi globaalia yksilöllisiin valintoihin pystyvää valkoista ruumista. (Ahmed 2000: 115-118.) Tanssista tulee liberaalin hybridisyyden ilmentymä, joka perustuu konsensukseen ja harmoniseen fuusioon. Häiritsevät, konfliktin mahdollisuuksia tuottavat erot torjutaan. (Ang 2001: 195, 198.) En kuitenkaan pidä fuusiotanssia sinänsä eroja torjuvana tai sulauttavana lajina. Tanssi saakin luennassani merkityksensä suhteessa projektin haasteelliseen monikulttuuriseen arkeen, joka verbalisoitui haastattelutilanteissa. Osallistuminen projektiin ei ollut edes mahdollista kaikenlaisille naisille, ja itse projektissakin toiminnan mahdollisuudet olivat eri syistä rajallisia. Tutkijan mielenkiintoa herättävä ambivalenssi liittyy juuri tähän ristiriitaan toisaalta eroja liikkeen avulla sulauttavasta tanssista ja toisaalta erojen edessä hämmennystä kokevan tanssintekijän välillä. 
Eräs suomalainen osallistuja tulkitsi Suorittaja-tanssia satiirina tai parodiana naisen elämästä ja naisia koskevista stereotypioista ja korosti tanssissa parodioitavan naisarjen universaaliutta (TKU/A/06/52:6). Se kuvaakin varmasti osuvasti monien ruuhkavuosiaan elävien suomalaisten naisten elettyä kokemusta sekä diskursiivisesti muotoutunutta käsitystä työn, kodin ja itsensä kehittämisen välillä tasapainoilevasta supernaisesta. Tiskivuoroihin kiteytyvä kiista kotitöiden tasapuolisesta jakamisesta saa tanssissa todenmakuisen representaation ja saa aikaan murtumia tasa-arvo -diskurssiin. Näitä tulkintoja voidaan lukea heteronormatiivisina ja perheellisten naisten elämää kuvaavina, mutta ajatus elämästä suorittamisena puhutteli kyllä muunlaisissakin elämäntilanteissa eläviä osallistujia (TKU/A/06/51:14). Työssäuupumisen ja burn outin diskurssit ruumiillistuvat tanssin lopussa, kun naiset kaatuvat uupuneina maahan: näin tanssi murtaa käsitystä suomalaisesta vahvasta naisesta. Voidaanko näitä parodioituja arjen aspekteja kuitenkaan sanoa universaaleiksi? Länsimaista feminismiähän on kritisoitu sen universalismista ja tavasta väittää puhuvansa kaikkien naisten puolesta moninaisista eroista välittämättä. (Morton 2000: 71-72; Mohanty 1991; 2002.)

Tanssissa nähtyjen uupumisen ja väsymisen teemoja voidaan lukea suhteessa projektissa tavoiteltuun monikulttuurisuuteen, jonka toteutumiseksi olisi tarvittu tavallista enemmän sekä henkisiä että aineellisia resursseja. Näin suuritöiseen hankkeeseen olisi kaivattu rahoitusta mahdollistamaan muun muassa monikulttuurisuuteen liittyviin ongelmiin paneutumisen. (TKU/A/06/51:15.) Tämä vaikutti projektilaisten väsymiseen ja uupumiseen, jota ei leimaa tanssilliseen arkeen liitetty parodisuus. Arjen uuvuttavuus - sekä marginaalissa eläviin maahanmuuttajanaisiin heijastettuna että monikulttuurisessa tanssiprojektissa koettuna - esti naisten tasavertaisen osallistumisen hankkeeseen. Joidenkin kohdalla arki esti jopa pääsyn projektiin.

Voisiko arki olla kuitenkin myös mahdollisuus? Arki käsitetään usein nimenomaan feminiiniseksi toisteiseksi tekemiseksi, joka ei vaadi suorittajaltaan reflektiota. Arki vain on, siinä ei ole mitään erikoista. Arki assosioituu ruumiillisuuteen ja materiaaliseen henkevän ja ylevän vastakohdaksi. (Jokinen 2003: 6-7 ja 2005: 27.) Rita Felskin mukaan arjen toisteisuus voi olla kuitenkin merkki myös toimijuudesta ja vastarinnasta, ja se voi olla keino suojella oman elämän arvokkuutta. (Felski 2000: 77-95; sit. Tiilikainen 2003: 64.) Esimerkiksi somalinaisten arkea tutkineen Marja Tiilikaisen mukaan arkirutiinien toisto saattaa todennäköisesti auttaa somalinaisia saavuttamaan tunteen järjestyksestä ja elämänhallinnasta maanpakolaisuudessa. Toisaalta heidän työtaakkansa on lisääntynyt kotimaassa tukeaan tarjonneiden ystävien ja sukulaisten tukiverkoston puuttuessa. (Tiilikainen 2003: 124-125.) Arkiset tilanteet voivat siis olla hyvinkin erilaisia, eikä universaalia naisarkea helpolla löydy. 


\section{Kulttuurisen representaation ongelmia}

Kysymykset kulttuuristen representaatioiden vastuullisuudesta ja eettisyydestä ovat tulleet entistä ajankohtaisemmiksi ${ }^{11}$ ja ne koskettivat myös Kuun taikoja -projektia sekä suunnittelu- että toteuttamisvaiheessa. Monikulttuuriseen esitykseen liittyy kysymys esitystraditioista ja eri kulttuurien mahdollisten sopivuusrajoitusten noudattamisesta. Projektin pääideoijan käymissä keskusteluissa mukaan pyydetyn somalinaisten liikuntaryhmän vetäjän kanssa tuli puheeksi, voivatko naiset ylipäänsä esiintyä lavalla, ja elleivät voi, miten heidän kulttuuriaan voitaisiin sitten tuoda näyttämöllä esille. (TKU/A/06/52:5, ks. myös Suutela 2002: 64 ja TKU/A/06/51:8.) Toinen projektin vetäjistä kommentoi tilannetta seuraavasti:

Ja siinäkin oli sitten semmonen mutka että pystyykö he olemaan siellä lavalla vai eikö pysty. Ja millä tavalla se heidän kulttuurinsa vois näkyä sitten, heidänkö esittämänä vai meidänkö jotenki viitteellisesti, vai oisko he vaan siellä lavalla tai joku mikä se oli, et siinäkin tuli yks kysymys. (TKU/A/06/52:5.)

Osallistujien erot esiintymiskokemuksissa saivat projektissa etnistetyn eron merkityksen. On somalinaisia, jotka voivat esiintyä, ja on myös suomalaisnaisia jotka eivät voi esiintyä tai joilla ei ole esiintymiskokemusta. Esimerkiksi yhden suomalaishaastateltavan kertoessa omasta tanssihistoriastaan tuli ilmi, että hänen lapsuudenperheessään Pohjanmaalla tanssi ei ollut "millään lailla hyväksyttävää ja sallittavaa, eikä tuettua", eikä hän nuorena aikuisenakaan uskaltanut ajatella sitä yhtenä ammattivaihtoehtona, vaikka haluja olisi ehkä ollutkin (TKU/A/06/50b:1, 2). Tanssikielteisyyttä on ja on ollut suomalaisessakin kulttuurissa tiettyinä aikoina tietyissä paikoissa, joten esiintymis- ja tanssikiellon sijoittaminen vain vieraan kulttuurin piirteeksi osoittautuu yhdeksi etnisen ja kulttuurisen eronteon tavoista.

Maahanmuuttajanaisten tiivis yhteys sukuihinsa ja kulttuureihinsa mietitytti suomalaisia tekijöitä:

Että semmonen varovaisuus että kuinka me, runnellaanko me jotain heidän kulttuuria, ja sitten se, että hyväksyykö suku sen, mitä nämä naiset on tekemässä, että mikä porukka me ollaan, hyväksyykö suku, että heidän kulttuurinsa edustaja on meidän kanssa tekemässä. (TKU/A/06/52:6.)

Varovaisuutta voi lukea merkkinä ambivalenssista, potentiaalisesta konfliktien ujuttautumisesta monikulttuurisen ja harmonisen rinnakkaiselon keskelle. Myös tietoisuus omasta valtapositiosta tulee esille: suhde "meidän" ja "heidän" välillä ei olekaan tasa-arvoinen, vaan me voimme juuri etuoikeutetun asemamme vuoksi tehdä väärin (ks. myös TKU/A/06/51:9).

Esitystutkimuksen piirissä on oma interkulturalistinen, kulttuurienvälisyyttä ja/tai monikulttuurisuutta korostava juonteensa (Bharucha 1993; Bharucha 2000; Holledge 
\& Tompkins 2000; Schechner 2002). Sen fokuksessa ovat olleet muun muassa kolonialistisista suhteista periytyvä hyväksikäyttö, kulttuurien fuusioituminen ja taiteen keinot ylittää kulttuurien välisiä rajoja. (Schechner 2002: 227.) Ohjaaja ja kriitikko Rustom Bharucha on arvostellut länsimaisten tekijöiden ei-läntisestä kulttuurista elementtejä lainailevia teatteriprojekteja uuskolonialismista, jossa kulttuuriset klisheet säilyvät jokseenkin koskemattomina (Bharucha 1993: 68). Craig Latrell näkee kulttuurisen lainailun tekijästä riippumatta ensisijaisesti luovana ja taiteellisena toimintana, jota ei tulisi tarkastella pelkästään poliittisen vallan ilmentymänä (Latrell 2000: 47, 52; ks. myös Holledge \& Tompkins 2000: 11). Hän peräänkuuluttaakin paikallisia kulttuurienvälisten kohtaamisten analyysejä, joissa kolonisoiva valta-asetelma ei olisi lähtökohtana, vaan joka tarttuisi esimerkiksi teatteriesitysten paikallisiin tulkintoihin (Latrell 2000: 54).

Kuun taikoja -esityksessä lasten esittämät taikaolennot puhuttivat niin suomalaisia kuin maahanmuuttajataustaisiakin haastateltavia, ja niiden kautta voidaan käsitellä projektilaisten ristiriitaisiakin näkemyksiä kulttuuria kunnioittavista ja toisaalta taiteellisen vapauden säilyttävistä representaatioista. Ennakkomainonnassa taikaolennot esiintyivät vielä jinneinä. ${ }^{12}$

Arabimaiden saduissa ja kansanperinteessä esiintyy zinni-hahmo. Näytöksessämme zinnit muuttavat arjen juhlaksi, surun iloksi ja tekevät monta muuta kepposta värittäen naisten arkea. (Kuun taikoja -ennakkomainos 2003.)

Maininta jinneistä poistettiin kuitenkin varsinaisesta käsiohjelmasta kiivaan keskustelun jälkeen, jossa maahanmuuttajanaisten yhteyshenkilö oli tuonut esille, että jinnit eivät helposti taivu kaikkien osallistujien mielissä vaarattomiksi satuhahmoiksi. Jinnit ovat islamilaisessa teologiassa Allahin luomia älyllisiä henkiolentoja, jotka voivat aiheuttaa ihmisille esimerkiksi sairauksia. Jinnejä pidetään nykyään kansanuskoon kuuluvina olentoina, mutta yhtä kaikki ne elävät joidenkin Suomessakin asuvien muslimien arjessa. (Tiilikainen 2003: 39, 236-241.)

Toinen maahanmuuttajanaisista koki, että hän olisi voinut olla projektissa avuksi nimenomaan oman kulttuurinsa tuntijana, mutta kukaan ei kysynyt hänen näkemyksiään esimerkiksi jinneistä. Tähän sisältyy oletus, että "natiiveilla" olisi hallussaan täydellinen pääsy kaikkiin kulttuurinsa merkityksiin ja siten voisivat täysin representoida eroaan muille (Ram 1999). Hän vakuutti myös ymmärtävänsä taiteeseen liittyvän luomisen vapauden, mutta näki tärkeäksi huomioida myös yhdisteltävien ja muokattavien elementtien muita merkityksiä.

Esityksessä oli monia asioita arabikulttuurista, joita en hyväksy, koska tunnen kulttuurini ja olisin voinut auttaa heitä. Olisin voinut auttaa arabikulttuuriin liittyvissä asioissa, tämä jinni esimerkiksi, tiedän mikä jinni kulttuurissani on eikä se ole sama kuin täällä. Mutta uskon myös että taiteessa voidaan keksiä ja luoda asioita, ei se ole ongelma, mutta olisi ollut parempi jos he olisivat kysyneet [minulta] jotain. (KT1:15. $)^{13}$ 
Lausuja esiintyi jinnejä koskevien ajatusten asiantuntijana ja ikään kuin kulttuurinsa omistajana. Suomalainen haastateltava taas korosti suomalaisten tanssintekijöiden vapautta ja oikeutta muuntaa arabikulttuurissa pelottaviksi ja vaarallisiksikin ymmärretyt hahmot fantasiahahmoiksi. "Lupaa" tähän oli kysytty aiheeseen perehtyneeltä tutkijalta, joka oli tuonut esille, että jinneillä on hyvin monia merkityksiä ja tulkintoja alkuperäisissäkin konteksteissaan. ${ }^{14}$ Asiaa oli pyritty selvittämään myös edellä itsensä marginalisoiduksi kokeneelta osallistujalta, mutta keskusteluyhteyttä ei ollut syntynyt. Tähän vaikuttivat ilmeisesti myös projektin suomalaisten tekijöiden keskinäiset ristiriidat. (KT3.)

\footnotetext{
Sen tähden ne zinnit oli siinä, et vaikka oli tiedossa se, että zinnit edustaa sitä ehkä niinku arabimytologiassa niitä semmosia ihan oikeesti vaarallisia ja pahoja otuksia ja hahmoja, jotka saattaa aiheuttaa ihmisille oikeesti vahinkoo. Niin jotenki tämmösenä suomalaisten tanssin, tai tämmösen näytöksen tekijöiden vapaudella niin ne sitten [--] muunnettiin tämmösiksi fantasiahahmoiks, zinneiksi, jotka niinku toimi tavallaan tämän olemassaolevan ja sit sen maagisen, näkymättömän maailman [--], niitten kahden maailman [--] energioiden kuljettajana. (TKU/A/06/52:6.)
}

Projektin arjessa jinnit loivat kuitenkin kaksi toisistaan erillistä maailmaa, jotka eivät kohdanneet, vaikka tarkoitus oli toinen. Loppujen lopuksi pienet lasten esittämät taikahahmot - vaikkei heitä jinneiksi kutsuttukaan - hypähtelivät tanssiesityksessä sekä omissa tanssinumeroissaan että viemässä tarinaa eteenpäin. Jinnejä voisikin ajatella ambivalenttina monikulttuurisuuteen liittyvän vaarattomaksi tekemisen metaforana: ${ }^{15}$ hyväntahtoisina taikaolentoina ne kääntävät pahan hyväksi, ja mahdolliset konfliktitilanteet saavat taianomaisesti kauniin ja juhlavan, estetisoidun eron hohteen ylleen (Root 1996: 19-20, 160). Jinnin vaarallisuutta ei voitu kuitenkaan täysin tukahduttaa.

Suomalaiset tekijät pyrkivät useammallakin tavalla varmistamaan, ettei kulttuurista hyväksikäyttöä tapahtuisi, mutta se ei estänyt marginalisoiduksi tulemisen kokemusta. Näyttäisikin, että erilaiset ymmärrykset monikulttuurisesta yhteistyöstä sekä suomalaisten tekijöiden keskinäiset valtapelit synnyttivät näitä ohipuhumisen ja marginalisoinnin hetkiä.

\section{Odotuksia ja pettymyksiä}

Tekijöiden tavoitteena oli sekä sukupuoleen että kulttuuriin liittyvien ennakkoluulojen purkaminen. Tämä ajatus korostui haastattelussa, jossa suomalaisnainen sanoi itämaisen tanssin ilmaisun olevan Suomessa varsin yksipuolista sukupuolen representoimisen suhteen. Taustalla tuntuu olevan stereotyyppinen, konservatiivinen käsitys miehen ja naisen välisestä suhteesta, naisten tehtävästä suvunjatkamisessa ja 
perheestä (ks. Laukkanen 2003a). Tätä käsitystähän edellä analysoidun Suorittajatanssinkin nähtiin parodioivan. Sovinistiseksikin luonnehdittava mielikuva naisesta aina ihanana, kauniina ja yliseksuaalisena ja miestä varten olemassa olevana ärsytti haastateltavaa. Näiden stereotyyppisten attribuuttien liittäminen erityisesti arabinaisiin vaatii purkamista, ja haastateltava näki tanssin yhtenä mahdollisuutena tuoda esiin muitakin ilmaisutapoja. Suomeen muualta muuttaneiden naisten mukaan saaminen projektiin olisi voinut rikkoa heihin liittyviä käsityksiä yllättävällä ja uudella tavalla. (TKU/A/06/52:6.) Paitsi että performanssit viittaavat aiempiin diskursiivisiin käytäntöihin, on niillä myös "mahdollisuus materialisoida jotain, joka ylittää tietämyksemme, mikä muuttaa asioiden tilaa ja kuvittelee muita, odottamattomiakin olemisen tapoja" (Diamond 2000: 67).

Niin kyllä mä jotenkin aattelin myös sitä, et jos niitä tulee niit naisia oikeesti sitten niistä maista, niin sieltä voi tulla jotain ihan yllättävää ja uuttakin, joka itse asiassa rikkookin sitä, mikä meillä on se kuva siitä, et mikä se on se arabinaisen ilmaisu, ja mitä hän välittää siinä tanssissa yleisölle. Mä aattelin et se ois ihana, kun se tulisi, tulisi esille. (TKU/A/06/52:6.)

Tekijöiden emansipatorisiksi luettavia tavoitteita oli myös naisten välisten erojen sekä ystävyyden ja yhteistyön korostaminen ainaisen kilpailun sijaan. (TKU/A/06/52:6.)

Kuun taikoja -tekijöiden korostama ryhmätyö sai prosessin edetessä erilaisia muotoja ja merkityksiä. Esimerkiksi toista maahanmuuttajanaisista motivoi projektiin mukaan mahdollisuus integroitua suomalaiseen yhteiskuntaan ja tutustua suomalaisiin naisiin (KT1:2,15). Yhteistyö ei ollut kuitenkaan sellaista kuin tekijät olivat kuvitelleet. Idean alkuunpanijat olivat suunnitelleet hyödyntävänsä ryhmätyömenetelminä toiminnallisia muotoja ja leikkiä mahdollisen yhteisen verbaalisen kielen puuttuessa. (TKU/A/06/52:6.) Edellä mainittu osallistuja esimerkiksi ei osannut juurikaan suomea projektin aikoihin mutta kylläkin erittäin sujuvaa englantia. Hän koki jääneensä marginaaliin, kun muut puhuivat pelkästään suomea (KT1:15). Ajatus ei-verbaalin toiminnan ja leikin universaaliudesta ja kyvystä ylittää kulttuuri- ja kielirajoja ei siis toteutunut. Tanssintutkimuksessakin on kritisoitu käsitystä tanssista ja ruumiin liikkeistä universaalina kielenä, joka ylittää sekä kulttuuriset että kielelliset rajat (esim. Kaeppler 1978; Williams 1991).

Myös tekijöiden erilaiset näkemykset yhteistyöstä toivat haasteita projektille. Osa projektilaisista kertoi kokeneensa olonsa ulkopuoliseksi: heistä tuntui, että kaikki päätökset oli aina jo tehty ennen kuin heiltä oli kysytty mielipidettä. (KT1:14,15; myös TKU/A/06/51:1.) Toinen maahanmuuttajista loikin oman kulttuurinsa tapaan toimia "oikeasti" yhdessä ja suomalaisten "ryhmätyöhön" voimakasta eroa. Oma kulttuuri näyttäytyi ideaalina, kun taas suomalaisessa ryhmätyössä kukin näyttää puuhastelevan yksin välittämättä siitä, mitä muilla olisi sanottavaa. (KT1:14,15.) 
Olin hieman turhautunut tai pettynyt, koska se ei vaikuttanut oikealta ryhmätyöltä. Projekti oli monikulttuurinen ja se tarkoittaa että ihmiset eri kulttuureista osallistuvat ja kertovat näkemyksiään ja tekevät asioita yhdessä, mutta todellisuus ei ollut sellainen. [--] Olin siis aika marginaalissa ja ryhmän tai projektin ulkopuolella. (KT1:15.) $)^{16}$

Oikea monikulttuurisuus määrittyy edellisessä lausumassa hyvin ideaaliseksi eikä siihen näytä kuuluvan konflikteja. Muutamat osallistujista ottivatkin vetäytymisen tietoiseksi strategiaksi konfliktiherkässä tilanteessa (KT1:14,15; TKU/A/06/50b:7). Marginalisoiduksi tulemisen kokemus vihastutti ja suretti, mutta sen tuominen esille olisi saattanut räjäyttää ristiriidat kaikkien nähtäväksi ja kuultavaksi. Säilyttääkseen edes jonkinlaisen työskentelyilmapiirin he osallistuivat vain sen verran kuin ajattelivat olevan välttämätöntä esityksen toteutumiselle. Monikulttuurisuuden toteutumiseen eivät siis ristiriidat kuuluneet vähemmistönkään mielestä, vaikkei valta- ja vähemmistöpositiosta käsin ole toisaalta edes mahdollista tehdä samalla tavalla väliintuloja ja osoittaa vääryyksien paikkoja.

Osa taas koki, että ryhmätyötä yritettiin, mutta kun ihmiset eivät näyttäneet olevan valmiita tekemään tansseja yhdessä alusta asti, esityksen ideoija ryhtyi töihin ja teki suuren osan koreografioista valmiiksi. Näytöspäivä oli kuitenkin jo päätetty, tilat varattu, eikä oikeastaan muuta mahdollisuutta enää ollut. (TKU/A/06/52:3,5.) Erojen tuomille ongelmille ei ollut tässä tilanteessa enää paljoa tehtävissä. Joillekin projekti näyttäytyi myös kaikkien halukkaiden ideoille avoimena tilaisuutena, jossa oli mahdollista toimia ja vaikuttaa (TKU/A/06/50a:7). Projektin päätyttyä useimmille osallistujille oli kuitenkin käynyt selväksi, ettei tässä projektissa päästy kovin syvälliseen kulttuurivaihtoon (TKU/A/06/50a:26). Olisi tarvittu enemmän aikaa muun muassa ryhmäytymiselle ja myös esiintymis- ja perustanssitekniikan hiomiselle. Tämä oli pettymys monelle projektin osallistujista (TKU/A/06/50a:26; TKU/A/06/51:2; TKU/A/06/52:10).

\section{Konflikteja ja kohtaamisia}

Toinen mukana olleista maahanmuuttajataustaisista naisista oli Amina, joka opetti ryhmälle omaa perinnettään, kurditanssia, joka sitten esitettiin Kuun taikoja -näytöksessä. Millainen tila hänelle tarjoutui projektissa purkaa kulttuuriaan ja sukupuoltaan koskevia stereotyyppisiä käsityksiä? Tai millaisen tilan hän otti? Näytöksessä esitetty perinteinen kurditanssi asettuu ensi näkemältä helposti taksonomisten esitysten joukkoon. Taksonomisen lajityypin esityksessä pyrkimys kulttuuristen välisten rajojen merkitsemiseen on voimakas (Holledge \& Tompkins 2000:112). Siinä lajityypilliset, kulttuurinmukaiset konventiot ovat rodullisessa ja kulttuurisessa vastaavuussuhteessa esittäjän ruumiin kanssa. Oikeannäköinen ruumis esittää sille kuuluvan esitystradition 
mukaista tanssia asiaankuuluvine pukuineen, maskeerauksineen ja musiikkeineen. Genreä luonnehtii ajatus autenttisuudesta. (Holledge \& Tompkins 2000: 114-115.)

Taksonominen esitys, joka on suunnattu länsimaiselle yleisölle, houkuttaa uusimperialistiseen, luokittelevaan katseeseen. Tämän katseen alla esittäjän ruumis sekä esitetty ruumis helposti nähdään yhtenä ja samana, jota voidaan lukea kulttuuristen ja rodullisten yleistysten kautta. Eli tanssijan "rodulla" on väliä, jos hänet luetaan kulttuurinsa alkuperäiseksi esittäjäksi. Hän ei esitäkään enää tanssia ja sen konventioiden mukaista ruumista, vaan tästä esityksellisestä ruumiista tulee hän itse. (Holledge \& Tompkins 2000: 113, 118; ks. myös Skeggs 2004: 292.) Kulttuurisen toisen tanssia esittäessä valkoinen ruumis määrittyy aina tiettyyn valtapositioon suhteessa visuaalisesti rodullisen luennan mahdollistavan kurdi- tai marokkolaisnaisen esitykseen. Suomalaisnaisen ruumis luetaan helpommin esittäväksi ruumiiksi, kun taas itämaiselta näyttävää tanssivaa ruumista luetaan useammin vain kulttuurinsa autenttisena edustajana. Rodullistetun tanssijan on paljon vaikeampaa tuoda esille, että kyseessä on esitys. (Wong 2002: 72; Holledge \& Tompkins 2000: 112, 118; ks. myös Ermutlu 2001: 36; Rastas 2002.) Pyrin seuraavassa osoittamaan, että kurditanssin merkitykset eivät kuitenkaan tyhjene siihen, että tanssin tulkitaan pelkästään uusintavan käsitystä muuttumattomista, toisistaan erillisistä kulttuureista (vrt. Bharucha 1993: 68; Meskus \& Paju 2002: 39).

Tässä tanssissa kurdinainen johtaa kolmesta suomalaisnaisesta ja yhdestä marokkolaisesta tanssijasta koostuvaa riviä. Tanssi jatkuu suoraan edellisestä Väsynyt-tanssinumerosta, josta jää lavalle suomalaista muinaispukua muistuttavaan, repaleiseen asuun pukeutunut Kirsi. Hän esittää edellisessä tanssissa yhtä kolmesta sairaasta naisesta, joita noita parantaa erilaisin liemin ja virvatulen avulla. Tanssin lopussa naiset ovat kuitenkin vielä toipilaita ja hieman voipuneita. Irakin kurdien koreaan asuun pukeutunut Amina tuo Kirsille kengät puettavaksi paljaisiin jalkoihinsa, ja kannustaa kurdin soranin murteella "rouvaa" mukaan tanssiin, jotta tämä paranisi ja saisi voimaa. Musiikin soidessa Amina näyttää Kirsille kurditanssin askelia. Kirsi yrittää pysytellä perässä, mutta välillä ilmeet ovat epätoivoisia, ja hän sanookin suomeksi tanssin olevan vaikeaa, eikä osaa. Amina kuitenkin kannustaa sinnikkäästi häntä.

Ensimmäisessä haastattelussa Amina pohti, että kenkäepisodi saattaa herättää muiden kurdien keskuudessa närkästystä, sillä ele on tulkittavissa siten, että kurdi on suomalaisen naisen piika. Suhde ei siis näyttäydy kurdien näkökulmasta välttämättä tasavertaisena. (KT1:9.) Tulkinta viittaa rikkaiden maiden naisten palkkaamiin köyhistä maista muuttaviin kotiapulaisiin, ja tuo siten esiin uuden aspektin arjesta ja siihen liittyvistä eroista (Ks. Jokinen 2005: 49). Toisella haastattelukerralla Amina esitti myös suomalaiseksi nimeämänsä tulkinnan, jonka mukaan hän tuo kengät vaivaiselle, mutta pikkuhiljaa parantuvalle suomalaiselle iloksi ja energian lähteeksi (KT2). Vaikka Aminaa aluksi harmitti epätasa-arvoisen tulkinnan mahdollisuus, hän loppujen lopuksi näki kuitenkin mahdollisuuden toimia kulttuurien välillä kääntäjänä 
ja tulkkina. Hän voi tarvittaessa selittää toiselle kurdille, että kyseessä on esitys, ja tähän esityksen luonteeseen ja kulkuun kuuluu tällainen siirtymä, jossa edellisellä tanssilla on merkitystä. Eli hän voi vaikuttaa tulkintoihin, joissa kenkien tuominen luettaisiin pelkästään naisten välisen epätasa-arvon osoituksena.

Ambivalenssi kenkäepisodin tulkinnassa johtikin asian uudelleen pohtimiseen ja vei mahdollisen konfliktin yli. Puhelinhaastattelussa tuli esille, että tämä mahdollisuus tuli Aminan mieleen vasta kun hän oli lukenut ensimmäisen haastattelun litteraation. Tutkimushaastattelu siis mahdollisti uudenlaisen, kulttuurien välisiä suhteita sovittelevan tulkinnan ja osoittaa myös kulttuurien joustavuutta. ${ }^{17}$ Kulttuuri, tässä tapauksessa esimerkiksi "kurdikulttuuri" ei ole jähmettynyt rakenne, jonka mukaan toimitaan, vaan toimijoiden tilanteissa muovaama ja muuttuva. Amina otti myös tietoisesti tällaisen välittäjän, kulttuurien välissä olevan paikan, joka toisaalta osoittaa käsitykseen alkuperäisistä ja pysyvämmistä tiloista "suomalaiset ajattelevat näin, kurdit noin", joihin Amina ei itse mahdu (Ang 2001: 4). Tässä voidaan puhua myös hetkittäisestä yhteismitattomuudesta (incommensurability) tai kommunikaation katkeamisesta, joka kuuluu aina eri tavalla positioitujen subjektien väliseen keskusteluun. Useimmiten kommunikaation katkeaminen saa jatkamaan ja tavoittelemaan täyttä, mutta koskaan saavuttamatonta ymmärrystä ja yhteisyyttä. (Ang 1997: 59.)

Osallistujien kulttuurisidonnaiset käsitykset taiteesta ja itseilmaisusta vaikuttivat varmasti siihen, että mukaan ei saatu paljoakaan muualta Suomeen muuttaneita naisia (Pääjoki 2004: 67). Yksi suomalaisosallistujista kommentoikin tanssiharrastajien ja ammattilaisten yhteistyötä lähtökohtaisesti epätasa-arvoisena. Tällainen yhteistyö olisi saattanut hänen mielestään olla hedelmällistä jos mahdollisiin ongelmiin olisi osattu varautua aikaisemmin. (TKU/A/06/51:15.) Myös osallistujien erilaiset taidot ja näkemykset tanssin opettamisesta ja oppimisesta asettivat haasteita yhteistyölle (esim. TKU/A/06/50a:24). Aminan vastuulla ollut kurditanssin opettaminen kiteytyi eroon perässä tanssimalla oppimisen ja toisaalta laskemalla sekä sanallisesti erittelemällä oppimisen välillä. Jälkimmäinen tapa tuntui Aminasta vieraalta ja vaikealta, ja hän kommentoikin toisten ulkomaalaisten oppivan tanssin ilman laskemista helposti kun taas suomalaisille pitää laskea askeleet ääneen. (KT1:2,10,14.) Kurditanssin opettamista ja oppimista kuvaavan jakson voi lukea tämän potentiaalisesti konflikteja tuottavan eron representaationa. Ero otetaan käsittelyyn ja sen lamaannuttava vaikutus häipyy ainakin hetkeksi. Loppujen lopuksi tuloksena on naisten yhteinen liike ja tanssin teemaksi kiteytyy ystävyys. Potentiaalisesti konflikteja ja ongelmia tuottava ammattilaisuuden ja amatööriyden välinen raja-aitakin on siis purettavissa, jos osapuolet ovat valmiita siihen (Pääjoki 2004: 64). Kurditanssi tarjosi mahdollisuuden tällaiseen kohtaamiseen, johon sisältyi ambivalenssi, tietynlainen outous vieraan edessä. (Ang 2001.) Sekä Amina että suomalaiset tanssijat antoivat kohtaamisen liikuttaa itseään ja erojen merkityksiä, muuttaa sitä, mikä tuntui aiemmin mahdottomalta. (Anthias 2001; Ahmed 2000.) 
Tanssimusiikkina oli kurdilaulaja Zakarian esittämä Helperke ${ }^{18}$ ja se lauletaan Etelä-Kurdistanissa puhuttavalla soranin murteella. Laulun tekstissä kerrotaan yhdessä tanssimisesta. Kappaleessa voi kuulla sekä perinteisiä kurdisoittimia että koneilla tuotettuja soundeja sekä rytmejä. Suomessa Amina on tanssinut kurditanssia naisten päivän juhlissa, kurdien uuden vuoden juhlissa newrozissa sekä poliittisissa tilaisuuksissa. Tanssin merkitys ei ole Aminalle kuitenkaan poliittinen, vaan se on hauskaa ja liittyy iloisiin asioihin, antaa voimaa. (KT2.) Tanssin voimaannuttava vaikutus näkyy Kirsin esittämässä hahmossa, joka juuri kurditanssia muiden naisten kanssa yhdessä tanssimalla saa energiaa ja paranee lopullisesti.

Kurditanssissa Aminalla on tietyin ehdoin mahdollista esittää sitä mitä hän osaa, välittää osaamistaan muille sekä pyrkiä hallitsemaan tanssin saamia merkityksiä. Projektin kuluessa aktualisoitui kysymys oikeanlaisesta kurditanssin esityksestä, kun Aminalle tarjottiin Turkin kurdien pukuja ryhmäläisten käyttöön. Amina identifioituu kuitenkin Irakin kurdeihin, joiden perinteeseen esitetty tanssi myös kuuluu, eikä Turkin kurdien pukujen käyttäminen tullut kysymykseenkään. (KT1:9.) Moninaisten vaiheiden jälkeen oikeanlaiset puvut saatiin käyttöön. Konfliktissa konkretisoituu muun muassa valtaväestön tapa ajatella kurdikulttuuria yhtenäisenä.

Tanssin kuluessa Amina on tanssinjohtaja, joka irrottaa välillä otteensa muiden tanssijoiden ketjusta ja siirtyy tanssimaan selin yleisöön. Tämä kuuluu Aminan mukaan perinteisemmin Irakissa miesten tanssityyliin, kuten myös esityksessä kuullut huudot. Huudot ja kiljaisut kuitenkin kuuluvat olennaisena osana tanssiin, ne tuovat siihen lisää voimaa ja energiaa, ja miesten puuttuessa naisetkin voivat niitä tuottaa. (KT2.) Välisoitossa, kun tanssijat irrottavat otteensa toisten käsistä, Amina ja marokkolaistaustainen Hanan kommunikoivat katseillaan ja vaihtavat paikkaa. Tämä luo erityistä yhteisyyden tuntua heidän välilleen, josta suomalaiset tanssijat jäävät ulkopuolelle. Tämän voi myös ajatella korostavan esittäjien ja esitettävän ruumiin vastaavuutta taksonomisen esityksen tapaan. Taksonomisen esityksen sisällä joka tapauksessa toisiksi luokitelluilla Aminalla ja Hananilla on mahdollisuus tulla esiin yksilöllisinä toimijoina, joilla on erityinen taito tanssia ja läheisempi suhde kurditanssiin kuin suomalaisilla enemmistön edustajilla. Toimijuus ja toiseuden rikkominen ovat siis mahdollisia tietyssä kontekstissa.

\section{Johtopäätökset}

Aluksi Kuun taikoja -projekti näytti epäonnistuneelta siitä syystä, etteivät marginaalisten toisten näkemykset tulleet kuulluiksi prosessin aikana. Valtakulttuurin edustaja ei pystynyt kuuntelemaan tarpeeksi hyvin ja oikein (Ahmed 2000: 156-157), mitä sanottavaa maahanmuuttajanaisella oli. Hybridisyyden välttämättömyyttä ja sen am- 
bivalenttia luonnetta korostavassa luennassa epäonnistuminen näyttäytyi toisessa valossa. Jos monikulttuurisuus ja kulttuurien välistä harmonista rinnakkaiseloa korostava ideaali on toiminnan lähtökohtana, kohtaamisessa eteen tulevat ongelmat ja joidenkin erojen ylitsepääsemättömyys ja yhteismitattomuus pyritään helposti torjumaan.

Esittävissä taiteissa ja tanssissa ambivalenssin torjunta voi tarkoittaa hankalien asioiden ohittamista ja vaikkapa kulttuurien esittämistä taksonomisen lajityypin konventioiden mukaisesti tai korostamalla harmonista fuusiota yhdistelemällä synkretistisesti eri elementtejä sieltä täältä. Toisaalta taksonomisetkin esitykset tarjoavat mahdollisuuden ja tilan - vaikkakin rajoitetun - tuoda esille ja muokata oman identiteetin rakennuspuita, kuten kurditanssin analyysi osoitti.

Monikulttuurisen arjen mahdollisuus näytti hyvin ristiriitaiselta, kun tarkastelin projektin arkea ja tanssillisesti esitettyä arkea rinnakkain. Ajatus universaalista arjen kokemuksesta törmäsi jo projektin alkumetreillä hyvin spesifeihin ja paikallisiin eroihin suomalaisten ja somalinaisten arjessa. Erot työntyivät esiin ambivalentteina tunteina mukaan myös myöhemmissä kohtaamisissa, eikä näitä potentiaalisia työstämisen paikkoja päästy purkamaan.

Jinneihin tiivistyi kysymys kulttuuristen representaatioiden vastuullisuudesta ja eettisyydestä. Kenellä on oikeus "vieraiden" kulttuuristen representaatioiden esittämiseen ja uudelleen tulkintaan? Voiko joku myöntää "luvan" esimerkiksi uskontoon liittyvien symbolien muuntamiseen? Milloin voidaan puhua kulttuurisesta haltuunottamisesta? Kiista oikeudesta jinnien tulkintaan näytti, että yksinkertaista vastausta kysymykseen ei ole. Voi olla myös niin, että kulttuurisina kiistoina näyttäytyvät asiat ovat osa henkilöiden keskinäisiä valtapelejä. Tutkimukseni kannalta kiintoisinta tapauksessa on kuitenkin se, millaisin argumentein kiista käydään. Tässä kiistassa kohtasivat käsitykset jinneistä toisaalta todellisina, koettuina henkiolentoina ja toisaalta vapaasti käytettävänä kulttuurisena symbolina, jonka merkitykset voivat vaihdella hyvästä pahaan. Jinneissä tiivistyi monikulttuurisiin kohtaamisiin liittyvä ambivalenssi.

Projektin osallistujilla oli paljon odotuksia siitä, millaista monikulttuurinen ryhmätyö voisi olla, millä keinoin kohtaamisia voitaisiin edistää ja mitä siitä voisi seurata. Odotukset liittyivät kulttuuristen, sukupuolitettujen ja etnisten erojen horjuttamiseen. Hyvä tarkoitus ei kuitenkaan toteutunut kaikin osin odotetulla tavalla, ja osa projektilaisista koki itsensä ulkopuoliseksi. Projekteissa vaaditaankin riittävästi tilaa konfliktien ja ambivalenttien tuntemusten selvittämiseen, jotta erojen voitaisiin antaa liikuttaa itseä, ja jotta jotain uutta voisi syntyä.

Monikulttuurisissa hankkeissa on otettava huomioon myös sellainen mahdollisuus, etteivät kaikki yksilöt ja kulttuuriset ryhmät ole välttämättä kiinnostuneita esittämään tai purkamaan itseään koskevia tulkintaketjuja taiteen keinoin vaan haluavatkin nähdä itsensä ennemmin erillisinä ja luonnollisina ryhminä. (Pääjoki 2004: 76.) Tässä projektissa monikulttuurisuus jäi miltei toteutumatta, koska sen tuli olla jotenkin näyttämöllä esitettävää. Ehkä projekti olisi toiminut toisin, jos ajatusta esityksen 
toteutumisesta ei olisi nähty niin perustavanlaatuisena koko projektin onnistumiselle. Tavallinen harrastaminen ja yhdessä tekeminen olisi voinutkin kiinnostaa myös niitä naisia - niin suomalaisia kuin muulta Suomeen muuttaneita, joille esiintyminen ei ole luontevaa. ${ }^{19}$

Kurditanssissa nousivat esille tekijöiden erilaiset tulkinnat muun muassa tiettyjen eleiden tai tietynlaisten kurdiasujen merkityksistä. Myös eroavaisuudet tanssin oppimisen tavoissa olivat potentiaalisia konfliktin paikkoja. Osa konflikteista otettiin kuitenkin käsittelyyn joko tutkimushaastattelussa, tanssiesityksessä tai projektin arjessa eikä niitä torjuttu. Häiritsevät erot saivat aikaan liikettä ja muutosta.

Luen ohipuhumisen ja konfliktien torjumisen strategioita ennemminkin projektissa lähtökohtana olleen monikulttuurisuusideologian tarjoamana toimintamallina kuin tekijöiden epäonnistumisena. Eriarvoisuuden tuottamien konfliktien ohittaminen voi myös näyttää ainoalta keinolta välttyä rasistiksi leimaamiselta. Kulttuurienväliseen kommunikaatioon kuitenkin kuuluu olennaisena osana se, että erot eivät ole välttämättä ylitettävissä tai käsiteltävissä ilman konflikteja. Tällöin juuri näiden konfliktien tulisi olla työskentelyn lähtökohta.

Kiitän professori Marianne Liljeströmiä, tutkijatohtori Petri Hoppua, FT Taru Leppästä sekä Etnomusikologian vuosikirjan arvioijia rakentavasta palautteesta artikkelin valmistumisen eri vaiheissa. Työtäni ovat taloudellisesti tukeneet myös Turun Yliopistosäätiö sekä Alfred Kordelinin rahasto. Artikkeli on valmistunut Suomen Akatemian tutkimusprojektissa Häiritsevät erot. Identiteetin, paikan ja vallan feministiset luennat.

\section{Viitteet}

1 Tanssista käytetään myös nimityksiä vatsatanssi ja napatanssi. Suurin osa suomalaisista tanssijoista suosii itse nimitystä itämainen tanssi sen maantieteellisestä ja kulttuurisesta epämääräisyydestä huolimatta.

2 Angin analyysi koskee Australiaa, jossa monikulttuurinen ideologia on ollut varsin näkyvä osa yhteiskuntaa ja poliittista järjestystä (ks. myös Ahmed 2000: 101-113). En väitä, että monikulttuurisuus ilmenisi tai toimisi Suomessa samalla tavalla kuin Australiassa, mutta näen että monikulttuurisen ambivalenssin käsite voi olla hyödyllinen suomalaisessakin kontekstissa. Monikulttuurisuudesta Suomessa ks. esim. Huttunen et al. 2005.

3 Haastattelusitaatit on muokattu helppolukuisemmiksi. Alkuperäiset haastattelunauhat ja litteraatiot yhtä lukuun ottamatta on arkistoitu Turun yliopiston Kulttuurien tutkimuksen laitoksen arkistoon.

4 Lapset ja nuoret olivat keskeisessä osassa projektia ja tekivät muun muassa omia tansseja sekä suunnittelivat puvustusta. Olen kuitenkin rajannut heidän osuutensa tämän artikkelin kysymysten ulkopuolelle.

5 Ryhmätyöskentelytapaa itämaisessa tanssissa ovat hyödyntäneet myös esimerkiksi helsinkiläisen itämaisen tanssin studion Tanssikeitaan tanssijat Kohtaaminen- ja Syke-esityksissään (Jakka 2003; Sirkiä 2004). Projektia olisi mahdollista tarkastella myös yhteisötaiteen näkökulmasta. Se ei kuitenkaan ole ollut varsinaisesti tekijöiden lähtökohta, joten tarkastelen projektia ennemminkin osana taideinstituutioiden marginaaliin sijoittuvaa itämaisen tanssin kenttää.

6 Jossain vaiheessa projektissa oli mukana vielä espanjalainen ja iranilainen nainen, mutta he jäivät pois.

7 Myös Kassandra 2000 -hankkeessa maahanmuuttajien osallistumista rajoittivat arkipäiväiset esteet: hankalat tapaamispaikat kaupungin keskustassa ja pitkät viikonloppusessiot (Meskus \& Paju 2002: 40).

8 Itämaisen tanssin tyypillinen aaltoileva liike, jota kutsutaan myös "kameliksi". 
9 Nimityksiä fuusio-oriental, Oriental Groove Mix (Tanssikoulu Jasmiina 2006), disco-oriental, fantasia (Seitsemän Hunnun Tanssi 2005). Esimerkiksi flamencovaikutteiden näkyminen tansseissa puvustuksessa ja käsien asennoissa on muodostunut lähes klisheeksi. Myös kolumbialais-libanonilaisen Shakiran nousu maailmanluokan poptähdeksi on näkynyt selkeästi itämaista tanssia ja disco- sekä jazz-tanssia yhdistelevän tyylin suosiona. Itämaisessa fuusiotanssissa käytettyä musiikkia ja liikekieltä leimaakin nimenomaan länsimaisen, lähinnä angloamerikkalaisen populaarimusiikin ja -tanssin vaikutus yhdistettyinä kulloinkin trendikkäinä pidettyihin etnisiin mausteisiin, viimeaikaisista esimerkkinä ns. Bollywood-vaikutteet.

10 Tiina Mahlamäki on käyttänyt termiä irtokarkkiuskonnollisuus kuvaillessaan eri perinteistä ammentavaa eklektistä uskonnollisuutta.

${ }^{11}$ Suomessa näitä kysymyksiä ovat herättäneet Ritva Siikalan ohjaamat näytelmät Sateenkaari (2000) sekä Aina jonkun tytär (2004). Sateenkaaren mediavastaanotosta kirjoittaneen Hanna Suutelan mukaan jotkut kriitikot epäilivät ohjaajaa kulttuuri-imperialismista ja "toisten" puolesta puhumisesta (Suutela 2002: 68). Aina jonkun tytär herätti taas muutaman somalivaikuttajan syyttämään ohjaajaa sekä näytelmässä esiintynyttä somalinaista somalikulttuurin ja islaminuskon halventamisesta (Airas 2003). Britanniassa nousi kohu birminghamilaisen teatterin esittämästä näytelmästä Häpeä (2004), joka kertoo seksuaalisesta hyväksikäytöstä ja sijoittuu sikhitemppeliin (HS 20.12.2004). Tanskalainen sanomalehti Jyllands-Posten julkaisi syyskuussa 2005 pilakuvan profeetta Muhammedista, joka sai aikaan alkuvuodesta 2006 valtaisan keskustelun mm. islamin halventamisesta ja sananvapaudesta. Jotkut brittiteatterit ovatkin ryhtyneet luetuttamaan näytelmäkäsikirjoituksia juristeilla ennen niiden ottamista ohjelmistoon (HS 7.3.2006).

12 Käytän omassa tekstissäni suomalaisessa keskustelussa (esim. Tiilikainen 2003) vakiintunutta kirjoitusasua "jinnit". Kuun taikoja -projektin kirjallisessa materiaalissa esiintyi tästä poikkeava muoto "zinnit", joten käytän tätä muotoa kuten alkuperäisissä lähteissä.

13 "There were so many things Arabic culture I don't approve that, because I know my culture and I could have served them. Serve them in some ideas concerning Arabic culture, because this is the "jinn" idea, I know what's jinn in my culture and it's not the same like there. But I all the time believe that in art you can invent things and create things and so, it's not a problem, but I would prefer that they would have asked something." (KT1:15.)

${ }^{14}$ Aladdinin taikalampun henki on myös yksi länsimaissakin tunnettu versio jinnistä. Jinni esiintyy tällaisena sarjakuvamaisena hahmona esimerkiksi Kuwaitissa julkaistussa arabiankielisessä Majid-lastenlehdessä, jossa henki ojentaa perinteiseen saudimiehen vaatteeseen sonnustautuneelle pojalle tietokoneen. Länsimaistuneet jinnit on siis valjastettu myös lapsiin kohdistuvan mainonnan ja siten lisääntyvän kuluttamisen edistäjiksi sekä hybridisen identiteetin symboleiksi arabikulttuurissa. (Peterson 2005.)

${ }^{15}$ Kiitokset tästä huomiosta Johanna Materolle.

${ }^{16}$ I felt always a little bit frustrated or disappointed, because it didn't seem real group work. The project was about monikulttuuri and it means that people from different cultures they would participate and give their opinions and do things together, but the reality was not like that. [--] So I was quite marginal and out of the group or the project. (KT1:15.)

${ }^{17}$ Haastattelusta luovana tapahtumana ks. esim. Eräsaari 2004: 77.

18 Zakaria 2003: Rojgâr.

${ }^{19}$ Näistä huomiosta kiitän Katariina Kyrölää, Mari Pajalaa ja Elina Valovirtaa.

\section{Tutkimusaineisto}

\section{HAASTATTELUT:}

KT1. Haastattelija Anu Laukkanen 22.4.2004, kesto n. 50 min. Ryhmähaastattelu. Nauha ja litteraatio tekijän hallussa.

KT2. Haastattelija Anu Laukkanen 21.8.2004, kesto n. 60 min. Puhelinhaastattelu, muistiinpanot tekijän hallussa.

KT3. Puhelinkeskustelu kesäkuussa 2006, palautetta artikkelin käsikirjoituksesta projektin vetäjältä. Muistiinpanot tekijän hallussa.

TKU/A/06/50a. Haastattelija Anu Laukkanen 19.4.2004, kesto n. 80 min. Ryhmähaastattelu.

TKU/A/06/50b. Haastattelija Anu Laukkanen 22.4.2004, kesto n. 40 min. Yksilöhaastattelu.

TKU/A/06/51. Haastattelija Anu Laukkanen 22.4.2004, kesto n. 60 min. Yksilöhaastattelu.

TKU/A/06/52. Haastattelija Anu Laukkanen 6.7.2004, kesto n. 85 min. Ryhmähaastattelu. 


\section{LEHTIARTIKKELIT:}

HS 20.12.2004 "Sikhit raivostuivat brittiteatterin näytelmästä."

HS 7.3.2006 "West End toipui pommi-iskuista ennen kauppoja."

\section{MUU KIRJALLINEN AINEISTO:}

Kuun taikoja -ennakkomainos (2003)

Kuun taikoja -käsiohjelma (2003).

Kuun taikoja -videointi näytöksistä (2003).

\section{AUDIOVISUAALINEN AINEISTO:}

Turun yliopiston Kulttuurien tutkimuksen laitoksen Uskontotieteen ja folkloristiikan äänitearkiston kokoelmat (TKU).

TKU/A/06/49a. Äänittäjä Anu Laukkanen 2.10.2003, kesto n. 90 min. Kuun taikoja-palautetilaisuus.

Zakaria (2003) Rojgâr. CD.

\section{Lähteet}

Adra, Najwa (2005) "Belly Dance: An Urban Genre.” Teoksessa Shay, Anthony \& Sellers-Young, Barbara (toim.): Belly Dance. Orientalism, Transnationalism \& Harem Fantasy. Costa Mesa: Mazda Publishers. Ss. 28-50.

Ahmed, Sara (2000) Strange Encounters. Embodied Others in Post-Coloniality. London and New York: Routledge.

Airas, Maija (2003) "Kassandra tuo uussuomalaisia taiteen kentälle". Campus 4/2003. http://home.cimo.fi/campus/1_2005/kassandra_print.html (luettu 5.1.2006).

Ang, Ien (1997) “Comments on Felski's 'The Doxa of Difference': The Uses of Incommensurability." Signs 1997, 23: 1 , ss. $57-64$.

Ang, Ien (2001) On not speaking Chinese. Living between Asia and the West. London \& New York: Routledge.

Anthias, Floya (2001) "New hybridities, old concepts: the limits of "culture". Ethnic and Racial Studies 2001, $24: 4$, ss. 619-641.

Bharucha, Rustom (1993) Theatre and the World: Performance and the Politics of Culture. London \& New York: Routledge.

Bharucha, Rustom (2000) The politics of cultural practice: thinking through theatre in an age of globalization. London: Athlone.

Diamond, Elin (2000/1996) "Performance and Cultural Politics". Routledge Reader in Politics and Performance. Toim. Lizbeth Goodman \& Jane de Gay. London \& New York: Routledge. Ss. 66-69.

Ermutlu, Yonca (2001) "Maahanmuuttajamusiikin näkymättömyys ja turkkilainen perinnemusiikin orkesteri Nefes". Steel pan, mbalax ja gamelan - tutkielmia maahanmuuttajamusiikeista. Toim. Erkki Pekkilä. Helsinki: Maailman musiikin keskus. Ss. 27-38.

Eräsaari, Leena (2004) "Antaudu vieteltäväkseni". Tutkija kertojana. Tunteet, tutkimusprosessi ja kirjoittaminen. Toim. Johanna Latvala, Eeva Peltonen \& Tuija Saresma. Nykykulttuurin tutkimuskeskuksen julkaisuja 79. Jyväskylä: Nykykulttuurin tutkimuskeskus. Ss. 59-87.

Felski, Rita (2000) “The Invention of Everyday Life.” Doing Time: Feminist Theory and Postmodern Culture. Toim. Rita Felski. New York: New York University Press. Ss. 77-98.

Holledge, Julie \& Tompkins, Joanne (2000) Women's Intercultural Performance: Cultural Double Cross. London \& New York: Routledge.

Huttunen, Laura (2004) "Kasvoton ulkomaalainen ja kokonainen ihminen: marginalisoiva kategorisointi ja maahanmuuttajien vastastrategiat." Puhua vastaan ja vaieta. Neuvottelu kulttuurisista marginaaleista. Toim. Arja Jokinen, Laura Huttunen ja Anna Kulmala. Helsinki: Gaudeamus. Ss. 134-155.

Huttunen, Laura, Löytty, Olli \& Rastas, Anna (2005) "Suomalainen monikulttuurisuus. Paikallisia ja ylirajaisia suhteita". Suomalainen vieraskirja. Toim. Anna Rastas, Laura Huttunen \& Olli Löytty. Tampere: Vastapaino. Ss. 16-40.

Jakka, Katariina (2003) "Rohkeaa improvisointia". Näytösarvio Kohtaaminen-näytöksestä 22.2.2003. Ishtar $3 / 2003$. 
Jokinen, Eeva (2003) "Arjen kyseenalaisuus". Naistutkimus-Kvinnoforskning 1/2003, ss. 4-17.

Jokinen, Eeva (2005) Aikuisten arki. Helsinki, Gaudeamus.

Kaeppler, Adrienne (1978) "Dance in Anthropological Perspective". Annual Review of Anthropology 1978/7, ss. 31-49.

Latrell, Craig (2000) “After Appropriation”. TDR: The Drama Review 2000, 44: 4, ss. 44-55.

Laukkanen, Anu (2003a) "Luonnollista liikettä, epäsopivia asentoja. Haastattelututkimus itämaisen tanssin liikekielestä Suomessa". Tanssi tanssi - kulttuureja, tulkintoja. Toim. Helena Saarikoski. Helsinki: Suomalaisen Kirjallisuuden Seura. Ss. 191-223.

Laukkanen, Anu (2003b) Arkirealismia taikamaailmassa. Näytösarvio Kuun taikoja -esityksestä 4.10.2003. Afsana $18 / 2003$.

Meskus, Mianna \& Paju, Elina (2002) "Juhlissa kohdataan". Kassandra - matka yli kulttuurirajojen. Toim. Hanna Suutela. Helsinki: Yliopistopaino. Ss. 33-43.

Mohanty, Chandra Talpade (1991) "Under Western Eyes. Feminist Scholarship and Colonial Discourses". Third World Women and the Politics of Feminism. Toim. Chandra Talpade Mohanty, Ann Russo \& Lourdes Torres. Bloomington: Indiana University Press. Ss. 51-80.

Mohanty, Chandra Talpade (2002) "'Under Western Eyes' Revisited: Feminist Solidarity through Anticapitalist Struggles". Signs 28: 2, ss. 499-535.

Morton, Stephen (2003) Gayatri Chakravorty Spivak. London \& New York: Routledge.

Peterson, Mark Allen (2005) "The Jinn and the Computer. Consumption and identity in Arabic children's magazines". Childhood 12:2, ss. 177-200.

Pääjoki, Tarja (2004) Taide kulttuurisena kohtaamispaikkana taidekasvatuksessa. Jyväskylä: Jyväskylän yliopisto.

Ram, Kalpana (1999) "Impossible Identifications: The University and 'Women of Difference"'. Communal / Plural: Journal of Transnational \& Crosscultural Studies. 1999, 7:2, ss. 213-230.

Rastas, Anna (2002) "Katseilla merkityt, silminnähden erilaiset. Lasten ja nuorten kokemuksia rodullistavista katseista". Nuorisotutkimus 3/2002, ss. 3-17.

Root, Deborah (1996) Cannibal culture: art, appropriation, and the commodification of difference. Boulder, CO: Westview Press.

Schechner, Richard (2002) Performance Studies: An Introduction. London: Routledge.

Seitsemän Hunnun Tanssi ry (2005) Itämaisen tanssin sanasto. http://www.7ht.fi/it/sanasto/ (luettu 2.3.2006).

Sirkiä, Liisa (2004) "Syke sykähdytti." Näytösarvio Syke-näytöksestä 28.3.2004. Ishtar 3/2004.

Skeggs, Beverley (2004) "Uneasy Alignments, Resourcing Respectable Subjectivity”. GLQ: A Journal of Lesbian and Gay Studies 10:2, 2004, ss. 291-298.

Suutela, Hanna (2002) "Sateenkaari - todistuksia suomalaisesta todellisuudesta". Kassandra - matka yli kulttuurirajojen. Toim. Hanna Suutela. Helsinki: Yliopistopaino. Ss. 53-71.

Tanssikoulu Jasmiina (2006) http://www.tanssikoulujasmiina.fi/ (luettu 2.3.2006).

Tiilikainen, Marja (2003) Arjen islam. Somalinaisten elämää Suomessa. Tampere: Vastapaino.

Williams, Drid (1991) Ten Lectures on Theories of the Dance. New Jersey: Scarecrow Press. 